\title{
Police call-takers' first substantive question projects the outcome of the call
}

\author{
Alexandra Kent \\ Charles Antaki \\ Keele University \\ Loughborough University
}

\begin{abstract}
Police call-takers need to gather as much data as is needed, as quickly as possible, to determine whether and what action should be taken. On analysing 514 calls to a UK centre handling emergency (999) and non-emergency (101) calls, we find that the call-taker's first substantive question already carries a diagnosis of the merits of the caller's case, and an implication of the call's likely outcome. Such questions come principally in four formats. On a gradient of increasing scepticism, these are: requests for the caller's location (which are treated as indicating that police action will be taken); open-ended requests for further information (treated as neutral); queries of the relevance of the incident or legitimacy of the caller, and reformulations of the caller's reason for calling (both projecting upcoming refusal of police action). We discuss the implications of this gradient for understanding how the calltakers manage their institutional goals. Data are in British English.
\end{abstract}

Keywords: Conversation Analysis, Requests, Scepticism, Projectability, Emergency Calls, Police

Dr Alexandra Kent

Alexandra Kent (a.kent@keele.ac.uk) completed her PhD in Discursive Psychology with Conversation Analysis at Loughborough University. She is currently a Lecturer in Psychology at Keele University. Her research interests include the negotiation of power and authority in interaction, requests, shared decision-making in interaction, and persuasive communication. She is currently working with the police to improve the effectiveness of communication during 999 and 101 phone calls.

Prof Charles Antaki

Charles Antaki (c.antaki@lboro.ac.uk) is Professor of Language and Social Psychology at Loughborough University, in the Department of Social Sciences. His research interests are in Conversation Analysis, and among his publications is the edited collection Applied Conversation Analysis: Intervention and Change in Institutional Talk (Palgrave Macmillan, 2011). 


\section{Introduction}

Customers and other service users may approach service-providers to address some 'problem' that they believe falls within the remit of the institution's scope of operations. However, not everything that customers or callers present will count as an actionable problem for the institution. This article investigates how police call-takers display probable alignment and mis-alignment with the caller's service request from the outset of the interaction.

Calls to the police typically fall into five distinct phases, first described by Zimmerman (1984): Following a reduced and specialised (1) opening/identification sequence (Wakin and Zimmerman 1999), callers formulate their reason for calling, typically framed as descriptions, requests, ambient events or combinations of the different types (Whalen and Zimmerman 1987). Regardless of its grammatical form, this first formulation is recurrently treated as a de facto (2) request for help (Heritage and Clayman 2010). The caller's 'request' is then subjected to an (3) interrogative series of question-answer pairs initiated and directed by the call-taker designed to establish the "policeable trouble" and any associated contingencies related to the police's response (Zimmerman 1984 p222). Once all relevant information has been gathered the call-taker announces the (4) remedy/response and the call then moves towards (5) closing (with or without unanimity, Raymond and Zimmerman 2016).

Previous research has established a strong basis for understanding the ways in which callers work to make their requests yield a preferred response. Zimmerman (1992) suggested that callers used their categorical status, specified by markers, labels and other indications of their status as someone who had rights to be taken seriously (for example, security personnel, eyewitnesses, and so on, compared to, say, callers reporting at third hand). More recently, conversation analytic studies, both of everyday talk (Heinemann 2006; Curl and Drew 2008) and emergency calls (Drew and Walker 2010; Larsen 2013; Raymond, 2014) have shown how speakers encode different degrees of entitlement to expect their request will be granted. Examples of highly entitled requests are I need/want $x$; of medium entitled requests $I$ would like / Can you x; and of less entitled requests I was wondering if $x$ / Would somebody be able to $x$. Larsen (2013) observed that when callers to the Danish emergency services (112) made overt requests without providing descriptions of the incident, high entitlement request forms elicited dispatch-relevant questions and low entitlement request forms elicited incidentrelevant questions. This work echoes similar findings in everyday conversations suggesting that high entitlement request formulations are structurally harder to resist (Craven and Potter 2010; Kent 2012).

The focus of previous work has been largely on how the caller's first formulation influences what happens; in this paper, we move the interaction forwards, and ask what the call-taker's first substantive question (the start of the interrogative series) implies for the eventual disposition of the request by the call's end.

\section{Method}

Our analysis is based on a corpus of 514 phone calls made to a regional UK Police force (142 emergency (999), 327 non-emergency (101) 45 from Fire/Ambulance services). All calls come to the same operators, but the 101 line is intended for police incidents that do not present an immediate and urgent risk to life or property (e.g., reporting crimes or traffic incidents, seeking advice, requesting visits from police officers). Call-takers are trained to handle 101 and 999 phone lines as well as operate the radio dispatch control system. 
Individuals vary their role each shift depending on operational requirements. The IT system indicates which phone line an incoming call is using (101 / 999 / Ambulance / Fire).

Participating call-takers signed consent forms to permit their calls to be used for the research. The calls were anonymised independently of the researchers to protect the callers' identity, as it would not always have been safe or ethical to interrupt the call to seek consent. All identifying features in data extracts have been replaced with fictitious information. The study received approval from Keele University's Ethical Research Panel and the participating police force.

\section{Data Analysis Procedures}

Call beginnings were transcribed using Jefferson conventions (Hepburn and Bolden 2017) and analysed using conversation analysis (Schegloff 2007; Sidnell and Stivers 2012) within a discursive psychology framework (Edwards and Potter 1992; Wiggins 2017). Call beginnings consist of everything said up to the caller's response to the first substantive question asked by the call-taker. As the analysis progressed subsequent turns were also transcribed as and when they became relevant.

We excluded the following calls from our collection during transcription and analysis:

- Abandoned or silent phone calls

- Outgoing police calls

- Calls via a text relay service for deaf callers

- Follow-up calls about ongoing incidents

- Calls with very unclear speech or poor phone connections where the conversation was disrupted with extensive repair initiators and corrections

- Calls where the first formulation indicates the call is not a request for action (e.g., "I don't want to report anything, I'm just looking for some advice about ..."). Here the call did not follow the same trajectory because it was not organised around soliciting assistance from the police as the central action.

\section{Analysis}

We argue that projectable outcomes to police calls are oriented to by both callers and calltakers from their first (non-greeting) utterances, and these orientations are highly consequential for how the conversation develops. We build on earlier analyses of callers' first formulations to describe some of their key features. Then, most of our analysis focuses on the first question the call-taker asks after the caller has delivered their first formulation (the beginning of what Zimmerman (1984) describes as the interrogative series).

\section{Callers' first formulations}

Although not our main focus, our dataset does facilitate analyses that extend and support earlier conversation analytic work on entitlement and request design. Our first 140 calls were systematically coded to statistically test and extend some of the qualitative observations drawn from prior work on caller's first formulations of their reasons for calling emergency services.

A key limitation of analyses of entitlement is that first formulations containing only a request without any contextual description of the incident are relatively rare, accounting for only $28 \%$ of the calls $(n=39)$ in our dataset. In our data descriptions of the incident (without requests) were the most common first formulation $(49 \%, n=69) .18 \%(n=25)$ combined 
requests and descriptions, and other formats were observed in $5 \%(n=7)$ of cases. These distributions are broadly consistent with Whalen and Zimmerman (1990) and Drew and Walker's (2010) characterisations of their US and UK emergency call datasets. Consequently request entitlement can only offer a partial explanation for how first formulations influence the trajectory of the call because it cannot account for the impact of incident-specific details. Nevertheless, to examine the utility of entitlement as an interactional resource, we explored how the entitlement displays encoded in both 'request-only' and 'requests with descriptions' formulations were distributed across our dataset.

Drew and Walker (2010) reported that almost all the explicit requests in their 999 calls used high entitlement formats. In our data, high/mid entitlement requests were significantly more common in 999 calls and low entitlement requests were more common in 101 calls, $\mathrm{X}^{2}(1, \mathrm{~N}=64)=4.328, \mathrm{p}=0.037$ (See Tables $1 \& 2$ in supplementary data). When faced with very serious or urgent situations, callers seem less likely to doubt their entitlement to seek help from the police. As serious matters are more often dealt with through 999, it makes sense to find a higher proportion of high/mid entitlement request formats there.

In our data we found that high entitlement requests were significantly more likely to receive responses that progressed the resolution of the incident, or assessed its seriousness. Less entitled requests were more likely to receive rejections, repair initiators, continuers, reformulations and responses that assessed the legitimacy or relevance of the request, $\mathrm{X}^{2}(2$, $\mathrm{N}=64)=6.155, \mathrm{p}=0.046$ (See Tables $3 \& 4$ in supplementary data). These results confirm Larsen's (2013) findings that request entitlement can (and does) have an impact on the trajectory of calls where the caller's first formulation contains an explicit request format. It also supports prior conversation analytic work on entitlement displays suggesting that high entitlement requests are more likely to receive aligned responses than less entitled requests (Heinemann 2006). The response they get tend to be better aligned to the caller's purpose or implied stance (Stivers, 2008) and are harder to resist or decline without triggering arguments or conflicts within the interaction (Kent 2012).

Entitlement displays within request formats offer a recurrent and normative practice for callers to display their stance towards the likely outcome of their request. At the same time as a caller makes a request they can also project their assessment of the likelihood of success. They are an efficient and effective resource to use during time-sensitive, high-stakes interactions like emergency calls.

Police calls do not move directly from request to granting/refusal. There is an interrogative insertion sequence "of question- answer pairs initiated and directed by the dispatcher [call-taker]" (Whalen and Zimmerman 1987 p175). Callers cannot rely on their entitlement display alone to mobilise assistance (Extract 1 is an exception). They will need to flesh out the grounds for their entitlement display with incident-specific information.

Requests and descriptions co-occurred during first formulations more often using lower entitlement requests, $X^{2}(2, N=64)=11.293$, $p=0.004$ (See Tables 5,6\&7 in supplementary data). This suggests that where callers display a low entitlement to expect assistance they are more likely to pre-emptively provide incident-specific information before the call-taker's first question. By providing event details (e.g., "a girl just beat me up in my house" P066) rather than making a request for assistance (e.g., "could I have the police please?" P025), the caller places the incident (rather than their personal rights/entitlement to expect police assistance) at the forefront of the interaction. Further work is needed to explore how descriptive first formulations might be designed to mobilise a positive police response (Stivers and Rossano 2010).

The rest of our analysis focuses on exactly what the call-takers do with the first formulation. We consider how call-takers use their first substantive question to signal their 
stance towards the likely outcome of the call and thus shape the trajectory and development of subsequent questions and answers.

\section{Call-takers' first substantive questions}

We present our analysis as a spectrum of call-takers' first substantive questions from those that strongly project immediate police assistance to those that strongly project refusal. For each extract we also describe the features of the caller's first formulation. We show that we need to go beyond the dimension of caller's entitlement and recognise that the call-taker is also judging the seriousness and relevance or legitimacy of the incident for the police.

\section{A) Call-takers' turns that most strongly project help being given: Dispatch-implicative questions}

The call-taker can't send help if they don't know where to send it to. By implication, if the call-taker asks for the caller's location, this is at least consistent with (and is pragmatically taken to be) their intention to act on it and send the required help. This can be seen in Extract 1 where the ambulance service has phoned the 999 line to request police assistance. A screen automatically identifies the call as coming from the ambulance service, hence the recognitional opening (line 1$)$.

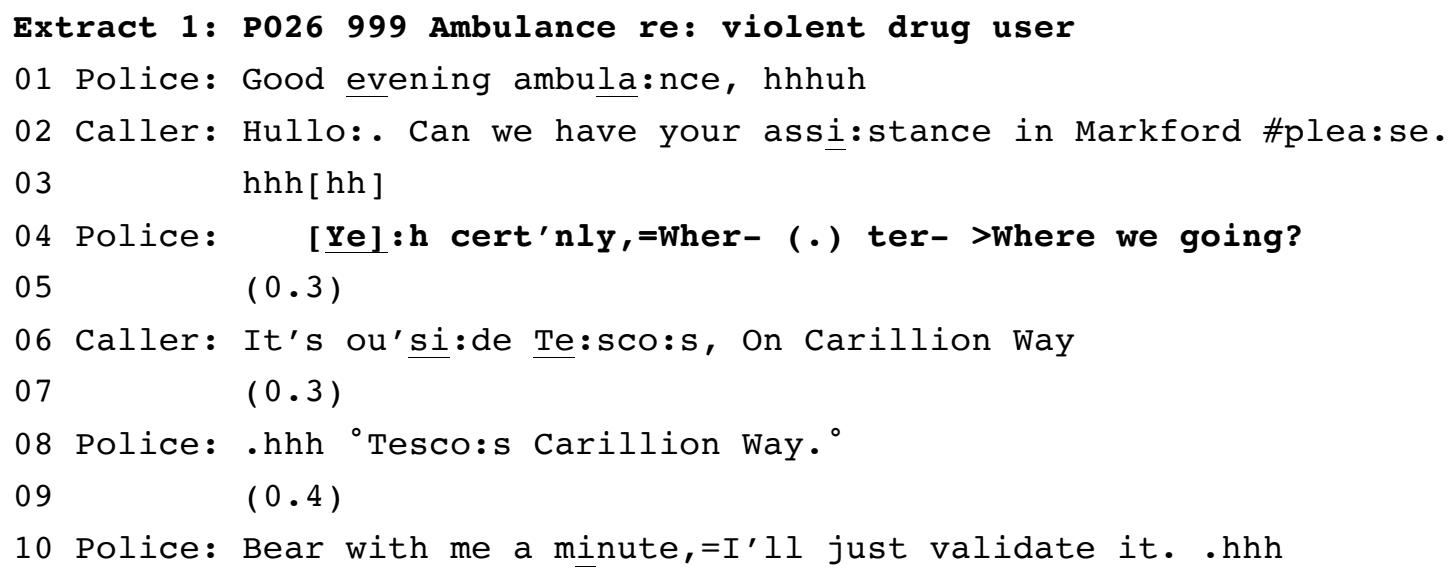

The exceptionally positive early granting in Extract 1 is a very rare phenomenon in our data ( $<10$ in 514 calls) where the call-taker's unqualified, immediate response is to grant the request. In most calls a more or less extensive interrogative series occurs between request and response. However, In Extract 1, as predicted by Zimmerman (1992) the use of the ambulance caller ID confers a categorical entitlement to expect police assistance.

Even without a unilateral commitment to action, asking for the caller's location still strongly projects granting. In Extract 2 the call-taker has merely asked for the location, but the caller nevertheless treats the call as having done its job, moving to a closing-implicative "hurry up".

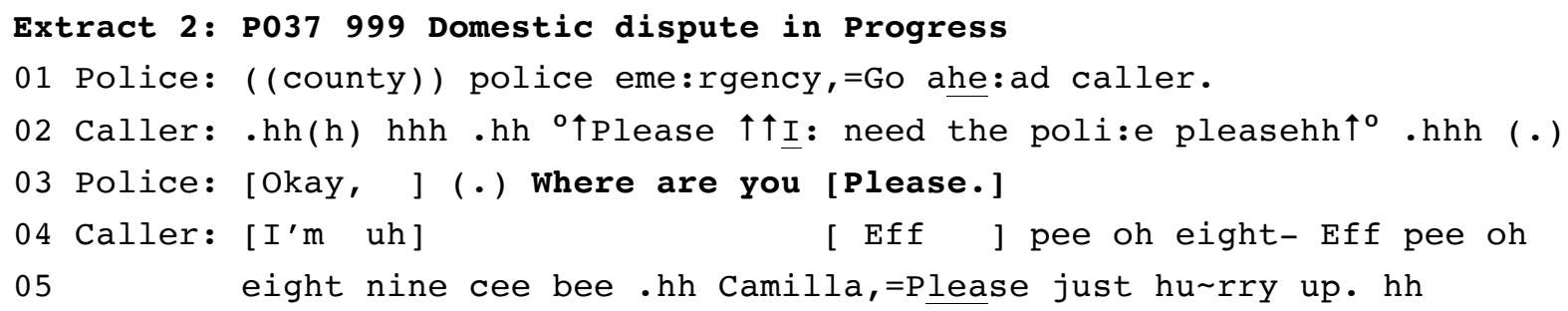


The caller uses a high entitlement request format to assert that police assistance is needed (line 2). No qualification or mitigation of the request is provided and there is no orientation to contingencies that might prevent the police from meeting this need (Curl and Drew 2008; Larsen 2013). The caller displays high levels of distress and upset, which are potential indicators that call-takers can draw on when assessing a caller's vulnerability and thus the seriousness or urgency with which the incident should be handled. The caller then provides her postcode, her first name and adds "Please just hurry up" (line 5). By seeking to hasten the dispatch of an officer, rather than confirm if one will be sent, the caller clearly considers her request to have been implicitly granted through the location solicit.

There is an important caveat to note here about the dispatch-implicative nature of location solicits (whenever they occur in the call); namely that they can be problematic when a caller then prematurely terminates the call, believing their request has been granted. Extract 3 starts with a mid-entitlement request-only format "Can I have the police please" - line 3). As Larsen's analysis (2013) predicts, this is not enough to trigger immediate granting and instead prompts a neutral information-seeking question ("what's going on mate" - line 4). Neutral first questions (like this one) are addressed in the next section. However, here we want to focus on what happens after the call-taker requests the caller's address (line 16 onwards).

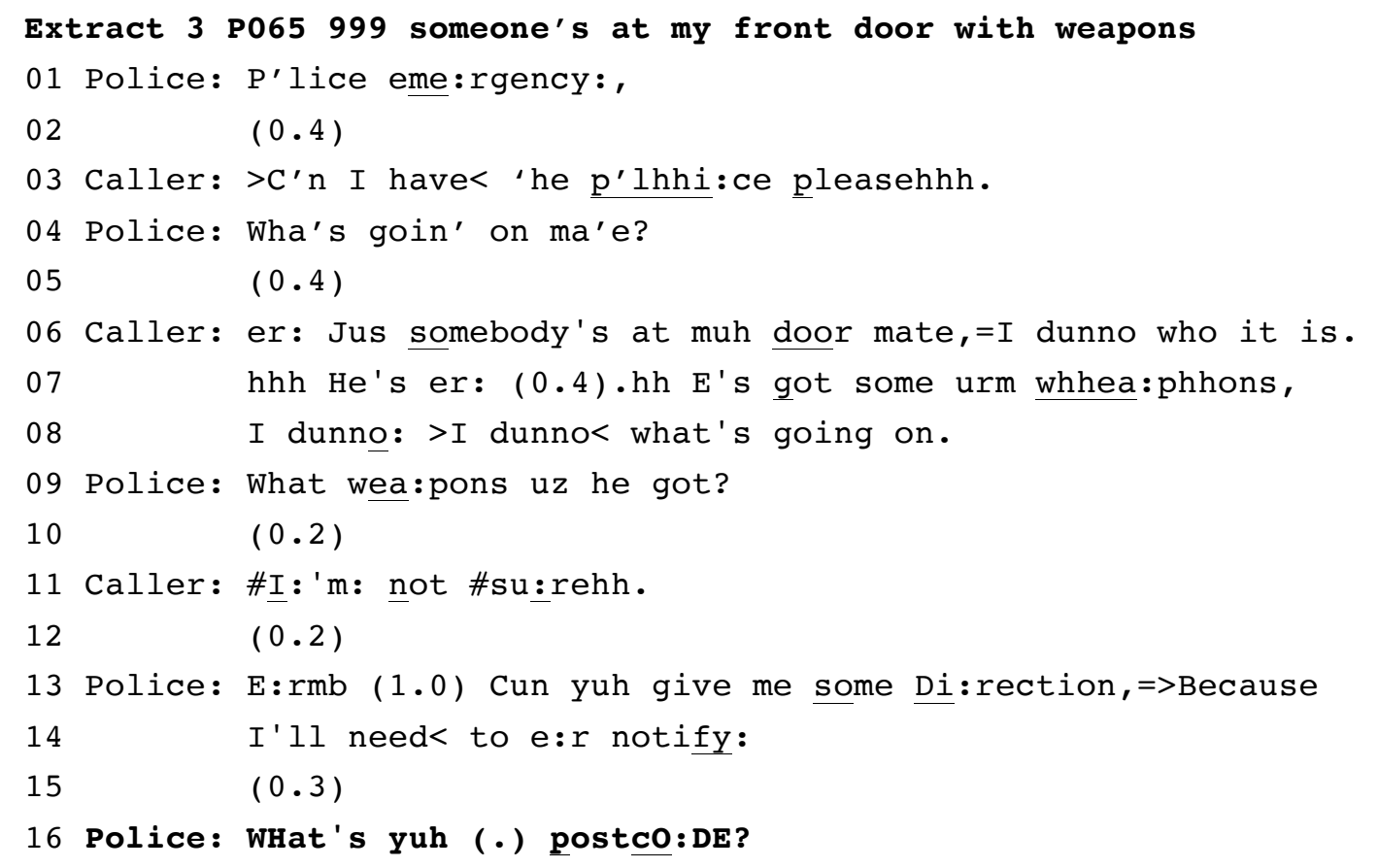

[talk specifying the exact address omitted]

31 Caller: Jus' try: and be qui:ck ple :ase.

$32(0.3)$

33 Police: Ye:s. >Yes, <=We'll 'ge' on to $i^{\prime \circ}$ as soon as we ca: n mate.

34 (6.9) - ((background loud voices))

35 Police: Izee tryna get in? u- Is he.

$36(1.5)-($ (background voices $))$

37 Caller: No.

$(4.0)-((\text { background loud voices }))^{i}$ 
Extract 3 is an important example of why police calls tend to have extensive insertion sequences between request and response. Call-takers typically gather information about the situation before formulating the outcome of the call to avoid precisely this situation: once the caller is satisfied that their request has been granted, their reason for calling is fulfilled and they move towards closing the call. This is problematic for the call-taker who has to create a detailed electronic record of all information pertinent to the case and gather sufficient information to assess risks to any officers who might be deployed to the scene.

Both callers and call-takers can use the topic of a question to indicate the projected outcome of the call. In particular, both parties often oriented to location questions as being highly dispatch implicative and therefore strongly project that the request will be granted. Due to the different functions of UK 999 and 101 lines, immediate dispatch of an officer is more likely during 999 emergency calls which often (but not always) relate to more serious and urgent matters. Across the data corpus, $32 \%$ of 999 calls and 5\% of 101 calls received an immediate or priority (within 1 hour) dispatch response. Many requests (particularly to 101) can be granted without dispatching an officer and might even be fully resolved within the call itself without needing further police action. Therefore it would be too simplistic to say that a location solicit always projects officer dispatch or request granting. Nevertheless, given the clear orientations shown within the data towards location-solicits as projecting request granting, call-takers should be aware of the signals their questions send and, if necessary, mitigate the implications.

\section{B. More neutral call-takers' first turns: Open-ended information solicits}

Moving through the first substantive question types, we are traversing a gradient of implications from granting assistance to refusing it. A mid-range option for call-takers was a neutral-seeming ('neutralistic', as Clayman and Heritage 2002 have it), 'what's happening?' type of question (as seen in Extract 3 above). These open-ended 'what-" questions prompt the caller to flesh out their first formulation. In most cases the fleshed-out version is sufficient for the call-taker to use a more implicative second question.

In Extract 4 the caller uses an elliptical formulation "Police at fifteen nolan street please" (line 3 ) to instruct police attendance. This avoids modal constructions that would position the decision to attend as within the call-taker's domain, nor does it orient to any contingencies that might prevent compliance. The caller's first high entitlement formulation displays full expectation that their instruction will be complied with (c.f., Heinemann 2006; Curl and Drew 2008; Craven and Potter 2010; Larsen 2013). She treats the location as the only relevant information about the incident required to secure police assistance. This is immediately treated as insufficient.

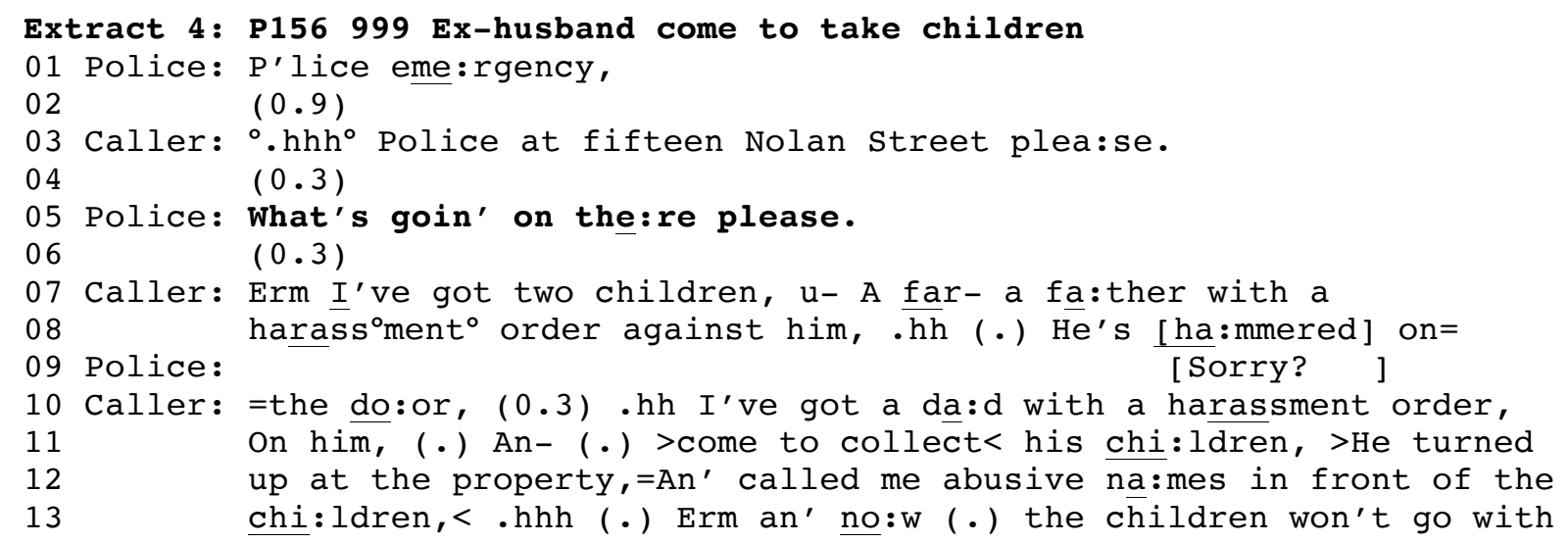




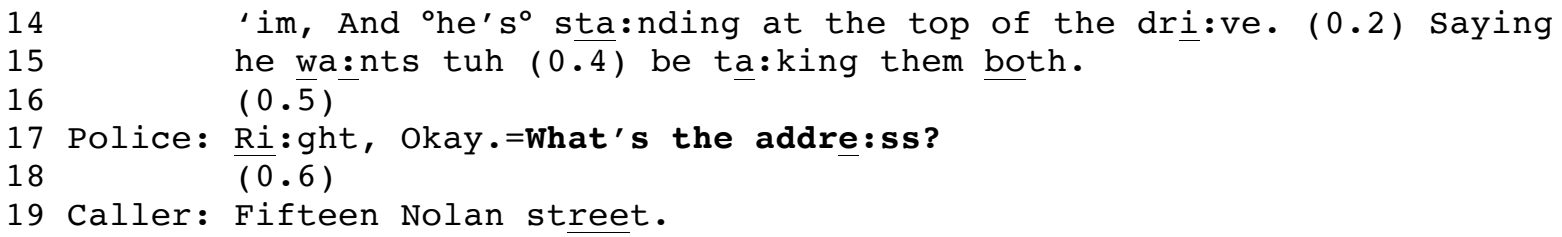

The lack of fit between caller's turn and call-taker's first substantive question is a recurrent feature of the calls in our data and marks a moment of disalignment. The caller's formulation is a high entitlement request, but unlike Extracts 1 or 2 her first formulation does not indicate any particular categorical warrant for her entitlement to expect police assistance (e.g., vulnerability/professional status) or incident-specific entitlement (e.g., current risk to life or property). Thus we see how in this context additional markers of seriousness or relevance might be consequential for whether a high entitlement format elicits a dispatch-implicative question.

Rather than granting the request, the call-taker uses a post-first insertion to make his response contingent on the caller's ability to describe a situation that would merit an immediate dispatch (Schegloff, 2007). In this sequential position he avoids confirming or resisting any implication that he might dispatch an officer by dis-attending to the location and instead soliciting information about the incident. Once the caller has described the incident (lines 7-15) the call-taker may then project police dispatch by asking for her address (line 17). This shows how each question and answer can change the trajectory of the call and the willingness of the call-taker to use a fomulation that projects a likely outcome.

Open-ended information solicits are designed to appear neutral by avoiding taking a stance towards the projected outcome of the call. They enable the call-taker to withhold or defer displaying a stance until more information has been provided. Extract 5 contains another open-ended first substantive question, but here the caller's answer prompts a more sceptical subsequent line of questioning from the call-taker. Questions that scrutinise the caller's role in, or the police-relevance of, an incident typically implicate rejection of the request. This illustrates a step further along our spectrum of increasingly rejectionimplicative question formulations.

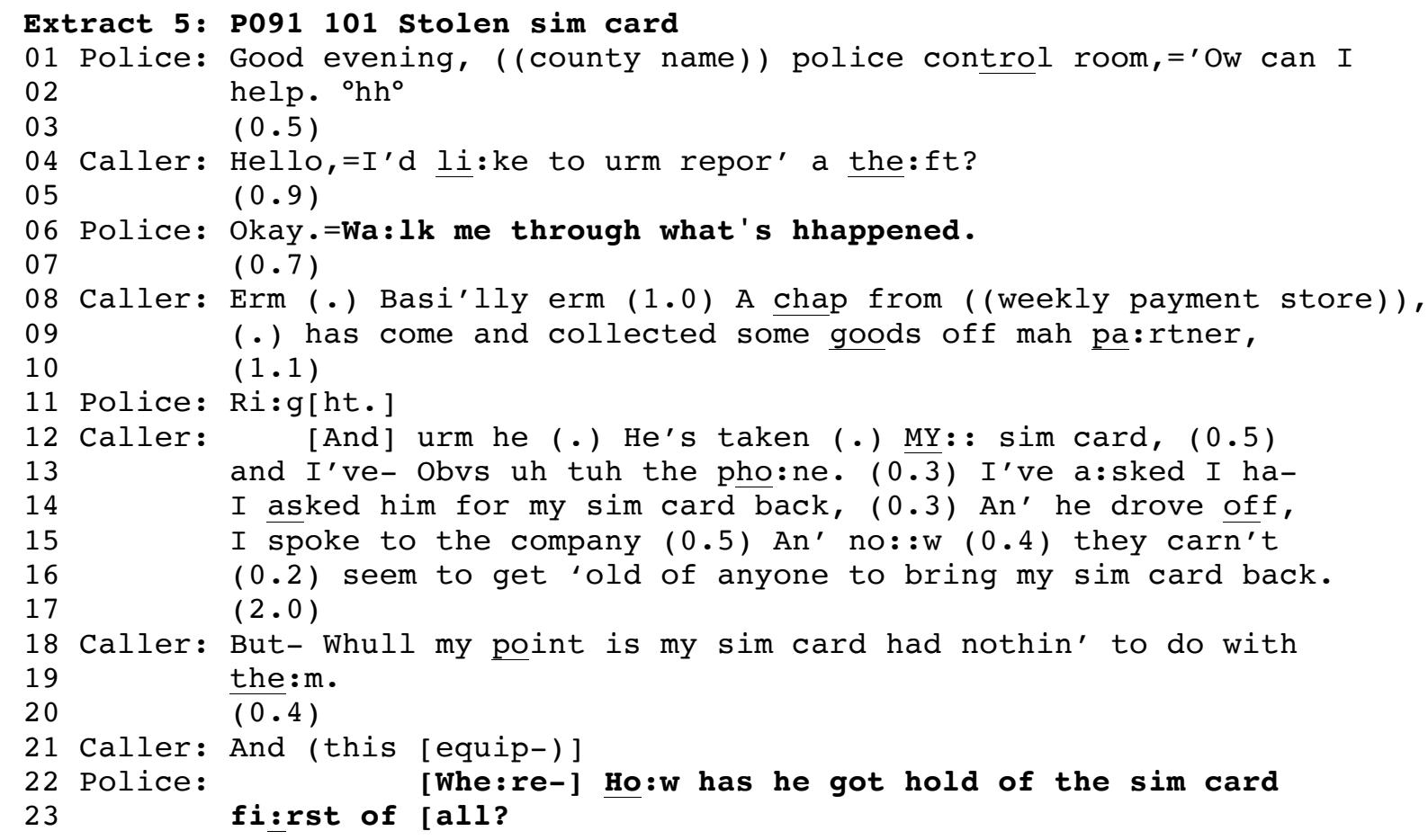


The caller's first formulation of the reason for calling is brief. It carries a fairly high entitlement by orienting to his desire to receive help rather than the call-taker's ability or willingness to provide assistance (Craven and Potter 2010). The police-relevance of the matter is minimally indexed through use of the crime category "theft", but no incidentspecific entitlements are suggested about the urgency, seriousness, or type of theft. The first formulation does not clearly furnish the caller with a victim-based categorical entitlement to expect assistance. ${ }^{\mathrm{ii}}$ In response the call-taker invites him to elaborate with further detail using the neutral "what's happened" formulation (line 6).

When a more detailed description is provided (lines 8-16) the call-taker initially waits (line 17). This delay itself indexes a possible dispreferred response (for the early setting-out of dispreference, see Sacks 1973and1987, and its development by Pomerantz 1984; for some quantitative evidence, see Kendrick and Torriera 2015). The caller tries to substantiate the theft by emphasising that the company has "nothing to do with" the sim card and that, by implication, they should not have taken it (lines 18-19). Following another non-response from the call-taker (line 20) he continues, but is interrupted mid-TCU by the call-taker's next question (lines 22-23). These sequential features themselves begin to indicate that the calltaker is not straightforwardly aligning with the caller's request. "How has he got hold of the sim card first of all?" signals that the status of the action as a 'theft' has not been firmly established to his satisfaction and that circumstances of the potential theft are now under scrutiny, including the caller's role in the transfer of the sim card. By casting doubt on the status of the incident itself, the call-taker's turn design does not project a high likelihood that the request will be granted based on the information provided so far.

The appended "first of all" to the end of the question on lines 22-23 helps highlight the importance of first questions. Here the call-taker does work to specifically mark this question as being a 'first' of some sort. Of all the questions that could have been prompted by the caller's telling, this is the one that the call-taker chooses to lead with. The deliberate consideration of the choice is made visible through the self-repair from "where" to "how", (line 22). It provides evidence that call-takers treat their first substantive question as an important barometer by which the trajectory of the call can be measured. It is their first chance to display their stance towards the incident and project the likely outcome of the call based on information provided so far. Here the call-taker works to replace his neutral first substantive question "walk me through what's happened" with a more sceptical one.

\section{C: The sceptical end of the gradient: Querying the caller's version of events or the relevance of calling the police}

As seen in Extract 5, call-takers' questions can have a subtle sharpness to them that probes into the foundation of the caller's account and signals it has not been unproblematically accepted as a factually complete description of a police-relevant matter. Our data contained several examples of first substantive questions that indicated doubt or scepticism about the caller's account of the incident from the start. These varied in the extent to which they assisted the caller to reframe their request into something that more clearly fell within the scope of relevant police action.

In Extract 6 the call-taker's first substantive question queries whether the caller is seeking a police-relevant form of assistance, projecting that her talk up to this point has not successfully convinced the call-taker that she is making a legitimate request for police assistance. Extract 6 exemplifies an extended narrative first formulation (lines 3-19). 


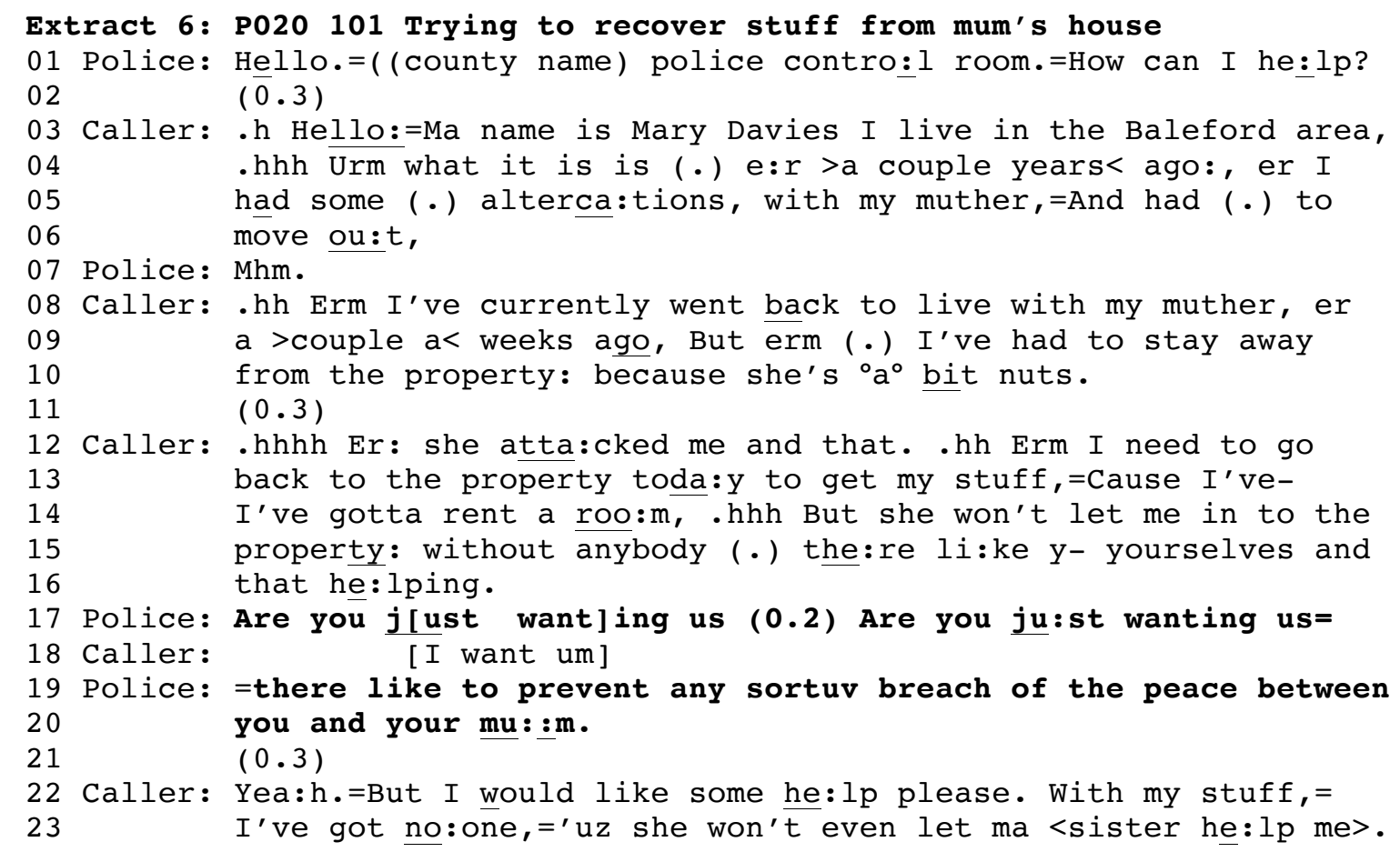

The caller's extended narrative characterises her mother as being dispositionally argumentative (lines 5-6) and physically dangerous (lines 10-12). She couches her request for assistance as rooted in her mother's obstructive unwillingness to allow her to return to the property without police accompaniment (lines 14-16). Callers can design their first formulations to construct themselves as deserving victims in need of support against an aggressor (Edwards 1997). Although the concept of deserving help has not been systematically applied to descriptive formulations, orientations to the doctorability of problems are routinely found in medical interactions (Heritage and Robinson 2006). We can see a similar orientation to 'innocent victim' and 'guilty perpetrator' being constructed here to mobilise police-relevant categories within the first formulation. Extract 6 reveals just how efficient the call-taker's choice of first substantive question can be at eliciting key information about the seriousness / relevance of the reason for calling. "Are you ju:st wanting us there like to prevent any sortuv breach of the peace between you and your mu::m." derails the caller's narrative account and both restricts and defines the type of police assistance the call-taker might be willing to offer (lines 17-20).

The call-taker's question problematises the unspecific "helping" sought in the caller's first formulation and sets boundaries on what can now be relevantly requested. By asking a focused question here rather than letting the caller continue her narrative or opting for a more granting implicative question (e.g., "where does your mum live?"), the call-taker indicates that the talk so far has not described a sufficiently relevant incident to mobilise police action and pushes the caller to do so - quickly. Furthermore, it (gently) conveys a inference by the call-taker that the caller's unspecified "helping" request might actually go beyond what the police would be willing to provide This inference displays scepticism towards the caller's request, projecting potential rejection. It also warrants the call-taker to curtail the narrative at this point and constrain the trajectory of the call (Pomerantz and Kevoe-Feldman 2017). The call-taker's inference is confirmed in the caller's answer that she had in fact been progressively building a request for help moving her belongings (line 22) based on her lack of familial support (line 23). 
The design of the question does, ostensibly at least, support the caller to reframe her request to become relevant for the police by naming a form of assistance that could be provided (preventing a breach of the peace). In contrast, we found several examples of sceptical first actions by call-takers that did not support the caller to build a police-relevant request.

\section{D: Reformulations}

Soliciting new information, of whatever sort, progresses the interaction by gathering additional details to base a future decision on. In contrast, a less aligning form of first action from the call-taker is to use a reformulation to query the caller's reason for calling when there is no clear problem in speaking, hearing or understanding. Such reformulations make available the implication that the formulation was insufficient to convince the call-taker that the matter warranted police action. Instead of soliciting new information to inform a decision, a reformulation problematises the known information, and so can be used to display scepticism towards the caller's request. Extract 7 "What d'ju me:an he's ly- he's lying on your doorstep" (line 14) includes one example of a partial reformulation couched as a clarification question.

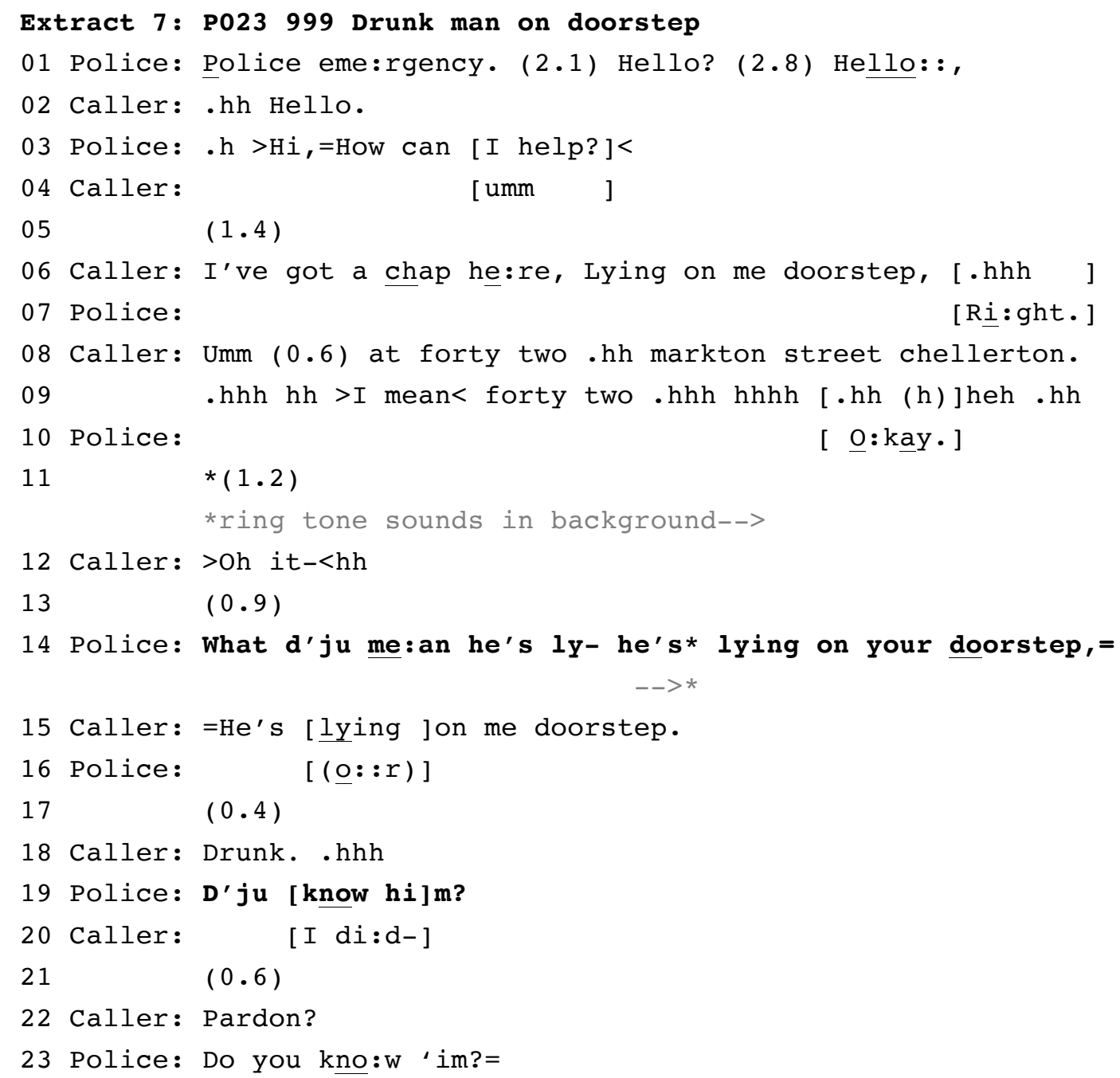

Although the caller's descriptive formulation does not assert an entitlement to request assistance, the unsolicited provision of her address (lines 8-9) implies that she is seeking police attendance. Her description of the incident does not recognisably relate to 
circumstances that are serious enough to relevantly require police assistance. The two receipt / continuer tokens ("Ri:ght" and "o:kay" - lines 7 and 10) provide opportunities the for caller to provide more relevant incident details. When this doesn't happen, the lack of orientation to seriousness or relevance is reflected in the call-taker's first substantive question: "What d'ju me:an he's ly- he's lying on your doorstep" (line 14). Although listed by Drew (1997) as an open-class repair marker, here "what d'ju mean" has something of combative tone (much like full repeats, as documented by Robinson and Kevoe-Feldman, 2010), and implicates a projected refusal of the request based on the information provided so far. Of relevance here is fact that the reformulation excludes the location information provided. Given the powerfully dispatch-implicative nature of locations within police calls, deleting it from the reformulation further signals the call-taker's scepticism around the seriousness or relevance of the described situation, and enhances the projection of refusal.

The caller's second formulation only adds that the chap on her doorstep is drunk, which also fails to clearly identify the situation as police-relevant. In this sequential context, the call-taker switches focus from the incident itself to the relationship between the caller and the drunk chap ("D'ju know him?" - line 19). Just as with "How has he got hold of the sim card first of all?" (Extract 5, lines 17-18), the switch from an incident-focused question to a caller-focused question signals that the caller herself is now under scrutiny rather than just what's happened.

Line 19 shifts the trajectory of the call away from dispatching police assistance towards a consideration of the caller's responsibilities to resolve her situation. The calltaker's question alludes to a culturally known script formulation (Edwards 1994) where you look after or manage a drunken person known to you, unless dangerous. On that basis police attendance is not indicated and the question does not project an outcome in which the police help.

Extract 8 illustrates a more overtly sceptical reformulation. Although the caller's first formulation alludes to criminal activity (drug dealing), several markers within his turn limit his entitlement to expect assistance. The caller's unusually casual greeting ("HOWA mmate? - Line 2") does not convey urgency or seriousness and is inconsistent with "an organisationally appropriate alignment" within an emergency call (Zimmerman 1992, p433). ${ }^{\text {iii }}$ The caller's use of a "tried" formulation suggests that his sister's attempt to plant drugs on him was unsuccessful, limiting the seriousness / relevance of the matter. His next TCU upgrades the matter to a more general dispositional accusation that his sister is a "drug dealer," which is a relevant categorical person reference for police action but lacks grounds for urgent or immediate assistance. Finally, his speech is slightly slurred with erratic volume control, possibly indicating intoxication, which limits his credibility as an informant.

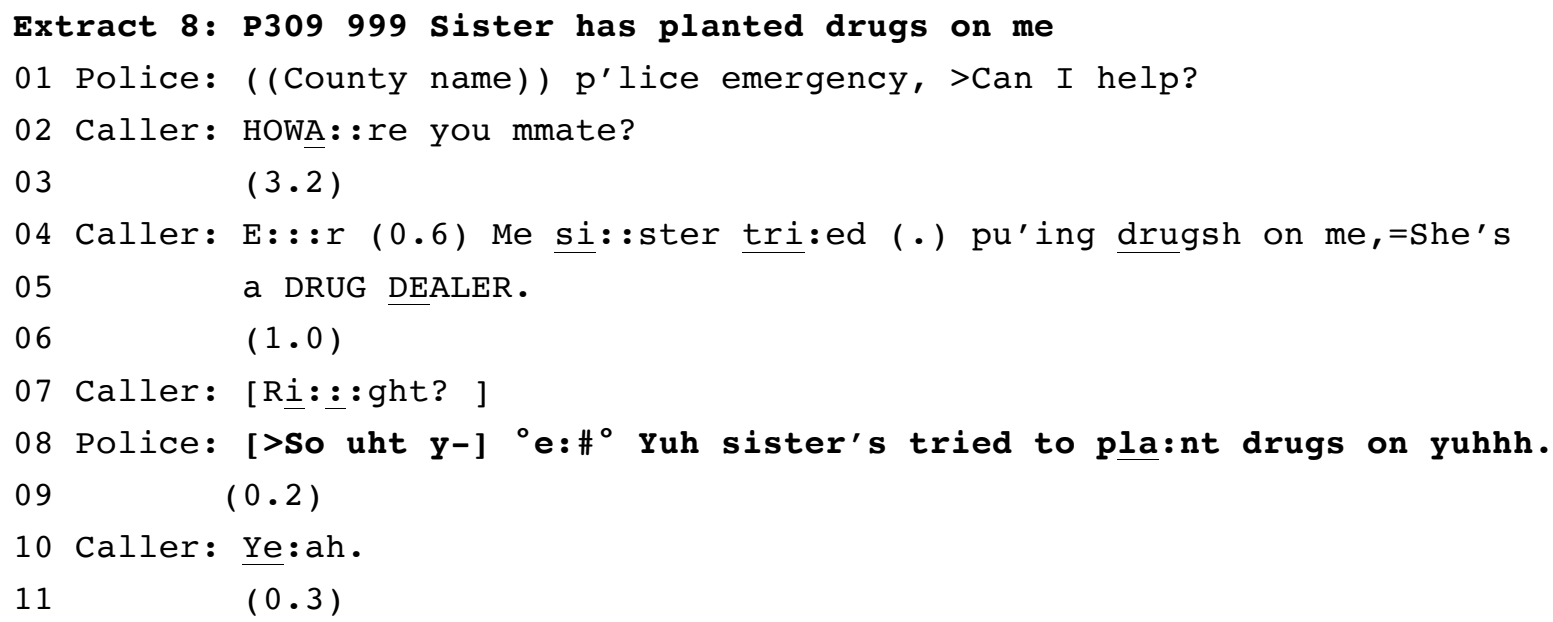




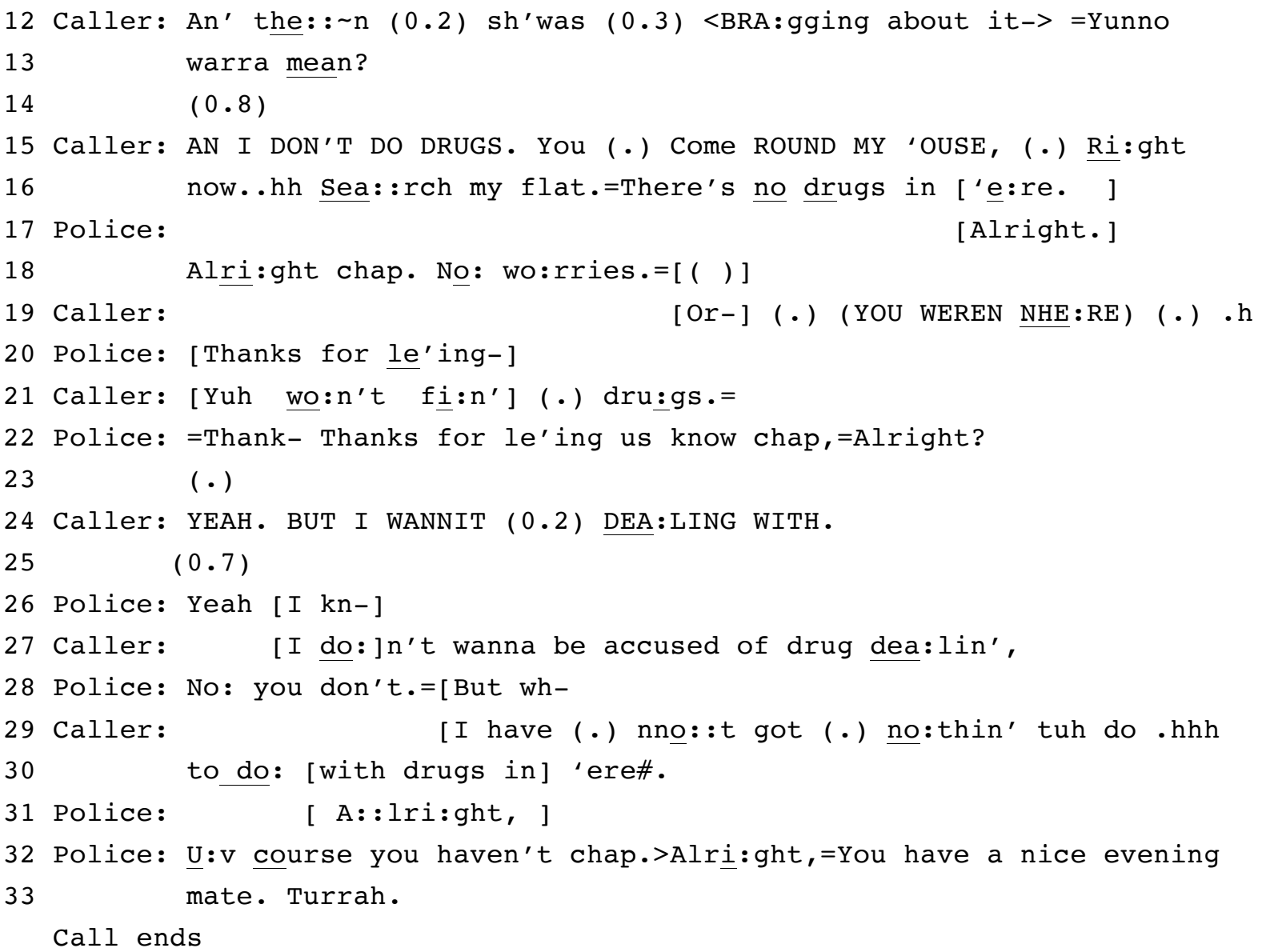

One line 8 the call-taker's partial reformulation disattends the dispositional accusation of a drug-dealing sister and concentrates on the single incident of attempted drug planting (line 8). The reformulation treats the claim as lacking an orientation to a sufficiently serious or relevant matter to warrant police attention. It positions the caller as needing to further justify their grounds for requesting police assistance. Holding someone to account for the information they've provided is a kind of "noticing" (Schegloff 1988) and is very different from asking them to elaborate. The call-taker's sighing prosody and lack of questioning turnfinal intonation signal that their interest, and possibly their credulity, has been exhausted.

Extract 8 contains the entire call, which supports our analysis of the call-taker's first action by illustrating the eventual outcome. After his reformulation, the call-taker does not ask any further questions about the incident. Instead he receipts the account (line 17), assesses it as not sufficiently serious to merit concern (line 18), thanks the caller for their civic action in reporting drug activity to the authorities (line 22) and moves towards closing the call without taking any details to facilitate future investigations. This highlights the vital importance of the first few turns of the conversation. In this case the call-taker's reformulation signalled an insufficiency with the caller's reason for calling and offered them a second opportunity to present something more substantial. No further opportunities were offered and the request was rejected.

\section{Discussion}

We set out to chart how the beginnings of emergency calls projected their likely end. The caller's first turn (or turns, if the call-taker withheld a substantive turn) provided sufficient evidence for the call-taker to issue a question on a gradient of scepticism about the policerelevance of the caller's request. A request for the caller's location was treated as projecting 
that the caller's request for assistance would be met. A request for more information could be neutral, or pave the way for scepticism according to the material that the caller then provided. Lastly, querying the caller's formulation of their problem, or their reason for the call, was taken to project that no assistance would ultimately be provided.

Our analysis has theoretical implications for conversation analysts relating to concepts of entitlement, projectability, and alignment. It also has applied implications for institutional call handling practice, including the emergency services.

\section{Entitlement, Seriousness and Relevance}

We confirmed Larsen's (2013) observation that high entitlement request formats are more likely to receive dispatch-implicative first substantive questions from call-takers than low entitlement request formats. This demonstrates the interactional power of entitlement displays, supporting prior work on how deontic authority (the right to make decisions and control actions) influences the trajectories of requesting / directing sequences (Stevanovic and Perakyla 2012). Unlike Larsen (2013) we included the full range of callers' formulations (including non-request formats) and focused our attention on the call-takers' first substantive questions, enabling us to suggest that displays of entitlement to expect assistance (both categorical and deontic) form part of a wider set of discursive resources drawn on by the calltaker to evaluate the seriousness of the matter and its institutional relevance.

In the absence of incident-specific details, request entitlement alone can (and does) provide a metric to position the call-taker's first substantive question along a gradient from projected acceptance to refusal of the request. However, when additional details about the incident are provided we see how call-takers' first substantive questions are calibrated to incorporate more than just considerations of request entitlement when projecting the likely outcome of the call. It highlights their focus on the seriousness of the matter and the institutional relevance of the request. As such our analysis unites work on request entitlement generally with work on requests in service encounters where participants have been shown to display a structurally organised orientation towards evaluating the seriousness and institutional relevance of the request (Tracy 1997; Jean 2004; Raymond and Zimmerman 2016). We begin to reveal the complex interrelationships between interactional institutional contingencies that impact the sequential organisation of talk during police calls.

\section{Projectability}

Our analysis shows that participants orient to the outcome of calls for help as projectable from the first turns of the conversation. The design of call-takers' first substantive questions, as well as soliciting important information on which to base their future decision, also telegraphs their current analysis of the likely decision. Many implications of first substantive questions are obviously also applicable when these questions occur in subsequent sequential positions within the calls. By restricting the examples presented here to the call-taker's first substantive question we highlight how quickly the likely final outcome becomes visible within the interaction and oriented to by participants. Both parties are constantly alert to what call outcome the talk is projecting on a turn-by-turn basis. Each question asked, and answer given, has the potential to shift the trajectory of the call either towards or away from granting the request. In many respects the careful monitoring of caller and call-taker towards the granting or refusal of the request mirrors the careful work done by parents and children to incrementally shift the trajectory of a directive sequence towards a mutually acceptable conclusion (Goodwin 2006; Goodwin and Cekaite 2013).

Conversation analysts have long accepted that "to engage in talk-in-interaction, as it unfolds in real time, participants rely on projectable units" (Ford 2004:27). Whether at the level of turn taking (Sacks, Schegloff and Jefferson 1974), adjacency pairs (Schegloff 2007), 
or the overall structural organisation of the interaction (Robinson 2013), we see how the progressive realisation of an action allows for the projection of what is yet to come. Our work contributes to this by illuminating how moment-by-moment contingencies influence both very local turn design of adjacent utterances and the wider projectable trajectory of the overall interaction.

\section{Alignment}

Constant monitoring of how each turn shifts the trajectory of the call is required by both participants to manage their stance towards either resisting or supporting the 'as yet unstated' outcome and to work towards eventually securing their preferred outcome. However, for many calls in our dataset there is no guarantee of a mutually satisfactory outcome. Neither the teenage son who wants his mother arrested for hiding his games console until he has cleaned his room, nor the person who wants the police to bring bolt cutters to release her jammed bike lock, are likely to have their requests granted.

Researchers across a range of institutional settings have described constant monitoring of the contingencies exposed by the interaction (e.g, Zimmerman 1992; KevoeFeldman 2015). Gentle tweaks to the trajectory can help maintain a basic sense of intersubjectivity and alignment as the various contingencies are resolved throughout the call. Other researchers have variously described a range of discursive resources used by interlocutors across the course of the interaction to work towards achieving a mutual goal in an environment of potentially competing interests. For example, pre-emptive commentary during doctors' physical examinations of patients (Heritage and Stivers 1999); implicit substitutions and embedded restriction prior to service refusal in calls to an airline booking service (Lee 2011), or customer upshot formulations following unresolved service requests in calls to a repair service (Kevoe-Feldman 2015). Our analysis locates the first murmurings of this trajectory management work in the earliest turns of the interaction, thus establishing such orientations as of primary importance for the successful accomplishment of the interactional encounter.

During aligned service encounters the lay-person (with direct epistemic access to the problem) provides case-specific information in response to interrogatives from an institutional representative who has no direct access to this case but has greater domainspecific epistemic expertise and holds the deontic authority to provide or withhold assistance. However, in non-aligned service encounters both parties attempt to present the most compelling arguments in favour of their position and to undermine the arguments put forward by their opponent (Hutchby 1996; Dersley and Wootton 2001; Reynolds 2011, 2015;). Nonaligned argumentative interactions are more likely to result in customer dissatisfaction, repeat calls, complaints, and poor decisions being made about when and how to render assistance (Svennevig 2012).

Within the call, if it becomes apparent that there is a misalignment between the participants about how the situation should be resolved, one or both parties are likely to begin resisting the preference organisation of the talk, disrupting the sequential progressivity of the interaction, and seeking to persuade the other party to change their stance towards the projected solution and align with their perspective rather than collaborate to achieve a mutually satisfactory outcome. As Raymond and Zimmerman (2016: 718) suggest the alignment (or not) of callers and call-takers' projects and identities "have broad relevance for interaction at virtually every level of organization in interaction: from the composition and organization of turns and sequences of them, up to the overall structural organization of episodes of interaction".

It's worth ending with how we might now explain a particularly powerful example of a call that goes very badly. This is the case documented by Svennevig (2012), showing the 
sequential progression of misalignment between caller and call-taker descending into open hostility. The consequences were fatal: a woman who had had a heart attack did not receive medical help because hostility between the caller and call-taker resulted in the police intervening in the situation first, delaying aid. As an addendum to Svennevig's analysis of misalignment, we contribute an observation about the opening turns of what would turn out to be the first in a series of increasingly conflictual calls. Note we start the extract at line 12, a little way into the call.

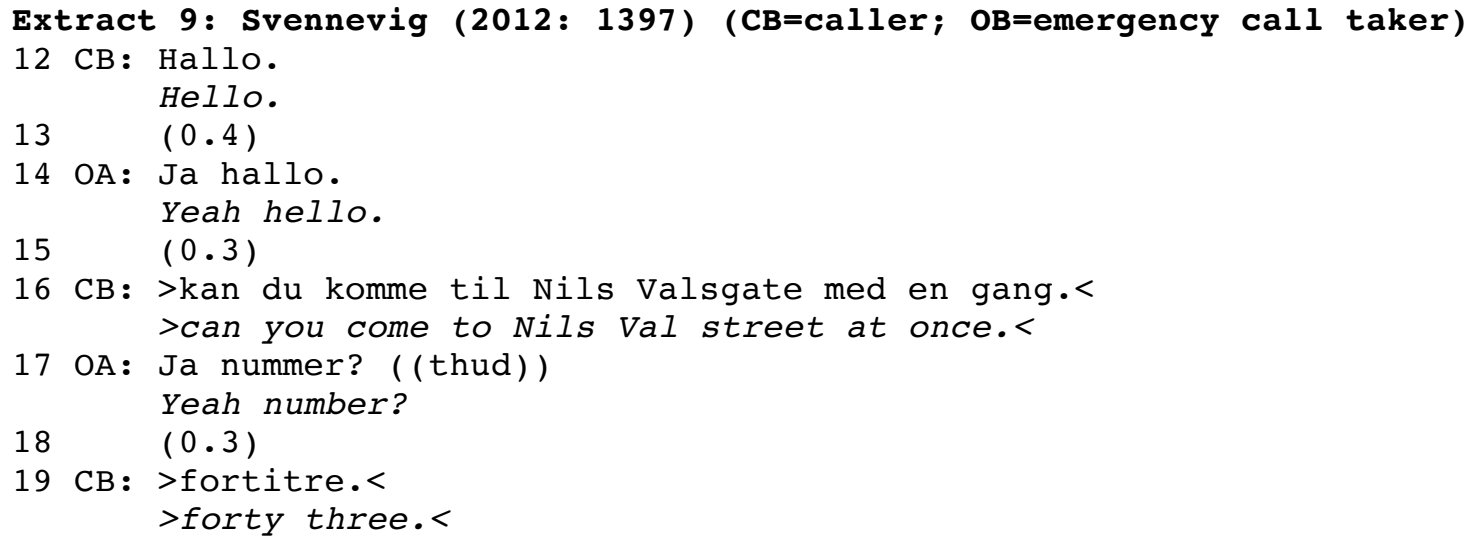

The speaker on line 12 is in fact not the original caller; that was a young adult woman, now replaced by (as it turns out later to be) her uncle. His taking over effectively deletes the calltaker's earlier, neutralistic, first substantive question to the woman, which we haven't shown ("Hva skjer der?" What's happening there?, line 7) and replaces it with the more grantingimplicative "Yeah number?" (on line 17) to the uncle. This location-identifying question has the consequence, we would argue, of setting up a projection towards granting the family's request. But the help is, as Svennevig shows, delayed by complications that escalate into hostility between the caller and the call-taker. Police are sent, family members are arrested, and by the time the ambulance gets to the address, the patient is beyond help. We suggest that the growing misalignment that Svennevig carefully documents has its roots right at the outset, in the apparently bland "Yeah number?". The crucial thing is that this seemed to make a promise; and as the caller and call-taker's alignments drifted out of synchrony, the caller treated as having been reneged on, fuelling resentment and the hostility that impeded rapid help.

\section{Concluding Comments.}

Our analysis helps identify the ethnomethods used by participants to gauge potential misalignment and, if necessary, prefigure future bad news as early as possible in the call (Maynard 2003). The implications of the call-taker's first substantive question maximises the early projectability of the outcome of the call for both participants and thus make available a far broader range of alignment-preserving strategies for tweaking the trajectory of the call without falling into argumentation or dispute.

\section{References}

Clayman, S. E. and Heritage, J. 2002. The News Interview: Journalists and Public Figures on the Air. Cambridge, England: Cambridge University Press.

Craven, A. and Potter, J. (2010). Directives: Entitlement and contingency in action. Discourse Studies 12(4): 419-442 
Curl, T. and Drew, P. 2008. 'Contingency and Action: A Comparison of Two Forms of Requesting', Research on Language and Social Interaction 41(2): 129-53.

Dersley, I. P. and Wootton, A. J. 2001. In the heat of the sequence: Interactional features preceding walkouts from argumentative talk. Language in Society 30: 611-638.

Drew, P. 1997. 'Open'class repair initiators in response to sequential sources of troubles in conversation. Journal of pragmatics, 28(1), 69-101.

Drew, P. and Walker, T. 2010. Citizens' emergency calls: Requesting assistance in calls to the police. In M. Coulthard and A. Johnson (Eds.), The Routledge handbook of forensic linguistics (pp. 96-110). New York: Routledge

Ford, C. 2004. Contingency and units in interaction. Discourse Studies. 6(1): 27-52.

Edwards, D. 1994. Script Formulations: An Analysis of Event Descriptions in Conversation. Journal of Language and Social Psychology, 13(3), pp211-247

Edwards, D. 1997. Discourse and Cognition. London: SAGE.

Edwards, D. and Potter, J. 1992. Discursive Psychology. Sage: London

Goodwin, M. H. 2006. Participation, affect, and trajectory in family directive/response sequences. Text and Talk 26(4-5): pp. 515-543.

Goodwin, M. and Cekaite, A. 2013. Calibration in directive/response sequences in family interaction. Journal of Pragmatics. 46 (1) pp122-138

Heinemann, T. 2006. 'Will you or can't you?': Displaying entitlement in interrogative requests. Journal of Pragmatics 38: 1081-1104.

Heritage, J. and Clayman, S. 2010. Talk in Action: Interactions, Identities, and Institutions, Wiley Blackwell: Chichester

Heritage, J. and Robinson, J. 2006. 'Accounting for the visit: giving reasons for seeking medical care', in J. Heritage and D. Maynard (eds), Communication in Medical Care: Interactions between Primary Care Physicians and Patients. Cambridge: Cambridge University Press: 48-85.

Heritage, J. and Stivers, T. 1999. Online commentary in acute medical visits: a method of shaping patient expectations. Social Science \& Medicine. 49. pp1501-1517

Hepburn, A. and Bolden, G. 2017. Transcribing for Social Research. Sage: London

Hutchby, I. 1996. Power in Discourse: The Case of Arguments on a British Talk Radio Show. Discourse and Society 7(4) pp481-497

Jean, Y. A. 2004. Inclusive intake screening: shaping medical problems into specialistappropriate cases. Sociology of Health \& Illness, 26(4) pp. 385-410

Kendrick, K. H. and Torreira, F. 2015. The Timing and Construction of Preference: A Quantitative Study. Discourse Processes. 52(4) pp. 255-289.

Kent, A. 2012. Compliance, resistance and incipient compliance when responding to directives. Discourse Studies, 14(6), 711-730.

Kevoe-Feldman, H. 2015. Closing the gap in customer service encounters: Customers' use of upshot formulations to manage service responses. Pragmatics and Society 6(1) 6788.

Larsen, T. 2013. Dispatching Emergency Assistance: Callers' Claims of Entitlement and Call Takers' Decisions, Research on Language and Social Interaction, 46:3, 205-230,

Lee, S. 2011. Managing Nongranting of Customers' Requests in Commercial Service Encounters, Research on Language and Social Interaction, 44:2, 109-134,

Maynard, D. W. 2003. Bad News, Good News: Conversation order in everyday talk and clinical settings. University of Chicago Press: London

Pomerantz, A. 1984. Pursuing a Response. In J. Maxwell Atkinson and John Heritage (Eds.), Structures of Social Action (pp. 152-164). Cambridge: Cambridge University Press. 
Pomerantz, A. and Kevoe-Feldman, H. 2017. Inferential work by 911 dispatchers: Soliciting the missing pieces. Presented at IPrA, Belfast, Ireland.

Raymond, C. W. 2014. Entitlement to Language: Calling 911 without English. Language in Society, 43(1), 33-59.

Raymond, G. and Zimmerman, D. 2016. Closing matters: Alignment and misalignment in sequence and call closings in institutional interaction. Discourse Studies. 18(6) 716736

Reynolds, E. 2011. Enticing a challengeable in arguments: Sequence, epistemics and preference organisation. Pragmatics 21:3.411-430

Reynolds, E. 2015. How participants in arguments challenge the normative position of an opponent. Discourse Studies. 17(3) 299- 316

Robinson, J. 2016. Accountability in social interaction. New York, NY: Oxford University Press.

Robinson, J. and Kevoe-Feldman, H. 2010. Using full repeats to initiate repair on others' questions. Research on Language and Social Interaction, 43(3), 232-259.

Sacks, H. 1973 [1987]. On the Preferences for Agreement and Contiguity in Sequences in Conversation. In Graham Button and John R. E. Lee (Eds.), Talk and Social Organisation (pp. 54-69). Clevedon, England: Multilingual Matters.

Sacks, H. Schegloff, E. A. and Jefferson, G. 1974. 'A Simplest Systematics for the Organization of Turn Taking for Conversation', Language 50(4): 696-735.

Schegloff, E. A. 1988. Goffman and the analysis of conversation. In P. Drew and A. Wootton (Eds.), Erving Goffman: Exploring the interaction order (pp. 89-135). Boston, MA: Northeastern University Press.

Schegloff, E. A. 2007. Sequence organization in interaction: A primer in conversation analysis. Cambridge, England: Cambridge University Press.

Sidnell, J. and Stivers, T. 2012. The Handbook of Conversation Analysis. Wiley Blackwell: Chichester

Stevanovic, M. and Perakyla, A. 2012. Deontic authority in interaction. Research on Language and Social Interaction 45(3): 297-321.

Stivers, T. 2008. Stance, alignment and affiliation during story telling: When nodding is a token of affiliation. Research on Language and Social Interaction, 47(1), 31-57.

Stivers, T. and Rossano, F. 2010. 'Mobilizing Response', Research on Language and Social Interaction, 43(1), pp3-31

Svennevig, J. 2012. On being heard in emergency calls. The development of hostility in a fatal emergency call. Journal of Pragmatics 44. pp1393-1412

Tracy, K. 1997. Interactional Trouble in Emergency Service Requests: A Problem of Frames. Research on Language and Social Interaction, 30(4), pp315-343

Wakin, M. A. and Zimmerman, D. H. 1999. Reduction and Specialization in Emergency and Directory Assistance Calls, Research on Language and Social Interaction, 32:4, 409-437

Whalen, M. R. and Zimmerman D. H. 1987. Sequential and Institutional Contexts in Calls for Help. Social Psychology Quarterly, 50(2) pp172-185

Wiggins, S. 2017. Discursive Psychology. Sage: London

Zimmerman, D. H. 1984. "Talk and Its Occasion: The Case of Calling the Police." In D Schiffrin (ed) Meaning, Form and Use in Context: Linguistic Applications. Georgetown University Roundtable on Language and Linguistics Washington, DC: Georgetown University Press. Pp. 201-08 in

Zimmerman, D. H. 1992. The interactional organisation of calls for emergency assistance, in P. Drew and J. Heritage (Eds) Talk at Work: Interaction in institutional settings, Cambridge University Press: Cambridge pp418-469 


\footnotetext{
${ }^{\mathrm{i}}$ Nothing in the background noises indicates an immediate threat to life or properly, nor does it precipitate an immediate departure from the call.

ii The brief and unelaborated formulation in Extract 5 becomes remarkable when compared with other first formulations used to report thefts in which information about the caller's victimhood is more clearly established through reference to their relationship to the stolen property (e.g. "my bike") the location of the theft (e.g., "my home") or the perpetrator (e.g., "I had some friends round"):

- "Hiya. I wanna ring up erm I've just been told by my wife my bike's been stolen from muh garage" (P003).

- "Um nh I want to report a theft of some money from my home" (P005).

- $\quad$ "Hello I was wondering if you could help me erm I had some friends round this evening and erm my phone's been stolen" (P173).

iii Although 67\% of callers' first formulations in our data contained minimal greetings, these were overwhelming delivered as turn initial particles (most notably yeah or hi) rather than as substantive turns. The FPP How are you (line 2) with space for a response (line 3) in Extract 7 is unusual, as is perhaps indicated by the call-taker's lack of response, and not characteristic of this type of interaction (Whalen and Zimmerman, 1987).
} 


\section{Police call-takers' first substantive question projects the outcome of the call}

\section{Supplementary Data}

Table 1: Summary of request formats

(Excludes first formulations that did not contain a request)

\begin{tabular}{llccc}
\hline Entitlement & \multicolumn{1}{c}{ Request format } & $\mathbf{1 0 1}$ & $\mathbf{9 9 9}$ & Total \\
\hline High & I need x & 2 & 2 & 4 \\
& Police please & $2(3)$ & $0(1)$ & 6 \\
\multirow{3}{*}{ Mid } & I want x (to report x) & $1(10)$ & & 11 \\
& I would like x (to report x) & 1 & 2 & 3 \\
& Can/could you x & $0(2)$ & $8(1)$ & 11 \\
Low & Can/could I x (report x) & 13 & 1 & 1 \\
& I could do with x & 6 & 1 & 7 \\
& I wonder if x & 2 & & 2 \\
& I hope / wonder if you could. [description] & 1 & & 1 \\
\hline & I'm looking for x & $\mathbf{4 5}$ & $\mathbf{2 3}$ & $\mathbf{6 4}$ \\
\hline
\end{tabular}

Table 2: Chi square analysis for Request entitlement $\mathrm{x}$ Phone line

\begin{tabular}{ccccc}
\multicolumn{4}{c}{$\mathrm{H} 1: \mathrm{X}^{2}(1, \mathrm{~N}=64)=4.328, \mathrm{p}=0.037$} \\
\hline Line & \multicolumn{4}{c}{ Entitlement } \\
High / Mid & Low & Total \\
\hline $\mathbf{9 9 9}$ & $\begin{array}{c}\text { Observed Count } \\
\text { Expected }^{\mathrm{i}} \\
\text { Count }\end{array}$ & 16 & 5 & 21 \\
$\mathbf{1 0 1}$ & $\begin{array}{c}\text { Observed Count } \\
\text { Expected Count }\end{array}$ & 21.1 & 8.9 & \\
\hline Total & $\begin{array}{c}\text { Observed } \\
\text { Count }\end{array}$ & $\mathbf{2 7}$ & 22 & 43 \\
\hline
\end{tabular}

Table 3: Distribution of call handler's $1^{\text {st }}$ response focus based on entitlement of caller's request ( $\%$ is based on no of requests with the same level of entitlement)

\begin{tabular}{|c|c|c|c|c|c|}
\hline \multirow{2}{*}{$\begin{array}{l}\text { First question } \\
\text { focus }\end{array}$} & \multirow{2}{*}{$\begin{array}{l}\text { First question (excl } \\
\text { continuers) }\end{array}$} & \multicolumn{4}{|c|}{ Entitlement } \\
\hline & & High & Mid & Low & Blank* \\
\hline \multirow[t]{3}{*}{ Progress Incident } & Dispatch relevant Question & $\begin{array}{l}17 \% \\
(\mathrm{n}=2)\end{array}$ & $\begin{array}{l}20 \% \\
(\mathrm{n}=5)\end{array}$ & $\begin{array}{l}4 \% \\
(\mathrm{n}=1)\end{array}$ & $\begin{array}{l}21 \% \\
(n=16)\end{array}$ \\
\hline & Incident relevant question & $\begin{array}{l}25 \% \\
(\mathrm{n}=3)\end{array}$ & $\begin{array}{l}8 \% \\
(\mathrm{n}=2)\end{array}$ & $\begin{array}{l}7 \% \\
(\mathrm{n}=2)\end{array}$ & $\begin{array}{l}3 \% \\
(n=2)\end{array}$ \\
\hline & Locating computer record & $\begin{array}{l}8 \% \\
(\mathrm{n}=1)\end{array}$ & 0 & $\begin{array}{l}19 \% \\
(\mathrm{n}=5)\end{array}$ & $\begin{array}{l}11 \% \\
(\mathrm{n}=8)\end{array}$ \\
\hline \multirow[t]{3}{*}{$\begin{array}{l}\text { Assess } \\
\text { seriousness }\end{array}$} & What crime? & 0 & $\begin{array}{l}24 \% \\
(\mathrm{n}=6)\end{array}$ & $\begin{array}{l}4 \% \\
(n=1)\end{array}$ & $\begin{array}{l}8 \% \\
(n=6)\end{array}$ \\
\hline & Seriousness? & $\begin{array}{l}8 \% \\
(\mathrm{n}=1)\end{array}$ & $\begin{array}{l}8 \% \\
(\mathrm{n}=2)\end{array}$ & $\begin{array}{l}11 \% \\
(\mathrm{n}=3)\end{array}$ & $\begin{array}{l}9 \% \\
(n=7)\end{array}$ \\
\hline & Urgency? & $\begin{array}{l}8 \% \\
(\mathrm{n}=1)\end{array}$ & 0 & $\begin{array}{l}4 \% \\
(\mathrm{n}=1)\end{array}$ & $\begin{array}{l}14 \% \\
(\mathrm{n}=11)\end{array}$ \\
\hline
\end{tabular}




\begin{tabular}{|c|c|c|c|c|c|}
\hline \multirow[t]{2}{*}{ Assess relevance } & Relevant? & $\begin{array}{l}17 \% \\
(n=2)\end{array}$ & $\begin{array}{l}28 \% \\
(n=7)\end{array}$ & $\begin{array}{l}15 \% \\
(n=4)\end{array}$ & $\begin{array}{l}17 \% \\
(n=13)\end{array}$ \\
\hline & Why are you asking? & 0 & $\begin{array}{l}4 \% \\
(n=1)\end{array}$ & $\begin{array}{l}11 \% \\
(n=3)\end{array}$ & $\begin{array}{l}5 \% \\
(n=4)\end{array}$ \\
\hline Reliability & Caller's Epistemic access? & $\begin{array}{l}8 \% \\
(n=1)\end{array}$ & $\begin{array}{l}8 \% \\
(n=2)\end{array}$ & $\begin{array}{l}11 \% \\
(\mathrm{n}=3)\end{array}$ & $\begin{array}{l}5 \% \\
(n=4)\end{array}$ \\
\hline \multirow[t]{3}{*}{ Reject } & Reject Request & 0 & 0 & $\begin{array}{l}11 \% \\
(n=3)\end{array}$ & $\begin{array}{l}7 \% \\
(n=5)\end{array}$ \\
\hline & Other & $\begin{array}{l}8 \% \\
(n=1)\end{array}$ & 0 & $\begin{array}{l}4 \% \\
(n=1)\end{array}$ & 0 \\
\hline & Total & $\begin{array}{l}100 \% \\
(n=12)\end{array}$ & $\begin{array}{l}100 \% \\
(n=25)\end{array}$ & $\begin{array}{l}100 \% \\
(n=27)\end{array}$ & $\begin{array}{l}100 \% \\
(n=76)\end{array}$ \\
\hline
\end{tabular}

* 'Blank' entitlement refers to first formulations that did not contain a request, but instead described the incident (e.g., P058 "I've been abused in the street by a neighbour who lives at the back of me")

Table 4: Chi square analysis for Request Entitlement $\mathrm{x}$ Focus of first substantive question $\mathrm{H} 2: \mathrm{X}^{2}(2, \mathrm{~N}=64)=6.155, \mathrm{p}=0.046$

\begin{tabular}{clcccc}
\hline $\begin{array}{c}\text { First substantive } \\
\text { question Focus }\end{array}$ & High & Mid & Low & Total \\
\hline $\begin{array}{c}\text { Progress Incident or assess } \\
\text { seriousness }\end{array}$ & Observed Count & 10 & 21 & 15 & 46 \\
\hline $\begin{array}{c}\text { Assess relevance, } \\
\text { reliability or reject request }\end{array}$ & Expected Count & 8.6 & 18.0 & 19.4 & \\
\hline Total & Observed Count & 2 & 4 & 12 & 18 \\
\hline
\end{tabular}

Table 5: Summary of formats for providing the reason for calling

\begin{tabular}{ccccc}
\hline $\begin{array}{c}\text { First Formulation } \\
\text { Format }\end{array}$ & $\mathbf{1 0 1}$ & $\mathbf{9 9 9}$ & Total & \% of total \\
\hline Request (Request to report*) & $10(17)$ & $10(2)$ & $20(19)$ & $28 \%$ \\
Request + Description & 6 & 5 & 11 & $8 \%$ \\
Description + Request & 10 & 4 & 14 & $10 \%$ \\
Description & 35 & 34 & 69 & $49 \%$ \\
Calling to Report & 2 & 2 & 4 & $3 \%$ \\
Other & 1 & 2 & 3 & $2 \%$ \\
\hline Total & $\mathbf{8 1}$ & $\mathbf{5 9}$ & $\mathbf{1 4 0}$ & $\mathbf{1 0 0 \%}$ \\
\hline
\end{tabular}

* We separated out requests for assistance (e.g., P052 "Can I have the police please") from requests to report an incident (e.g., P017 "I'd like to report an assault please")

Table 6: Distribution of request entitlement and first formulation

\begin{tabular}{lcccc}
\hline $\begin{array}{c}\text { First Formulation } \\
\text { Format }\end{array}$ & High & Mid & Low & Total \\
\hline Request (report request) & $5(4)$ & $7(13)$ & $8(2)$ & $20(19)$ \\
Req + Desc & 1 & 3 & 8 & 12 \\
Desc +Req & 2 & 2 & 9 & 13 \\
\hline \multicolumn{1}{c}{ Total } & $\mathbf{1 2}$ & $\mathbf{2 5}$ & $\mathbf{2 7}$ & $\mathbf{6 4}$ \\
\hline
\end{tabular}


Table 7: Chi square analysis for Request entitlement $\mathrm{x}$ First formulation format

\begin{tabular}{cccccc}
\multicolumn{6}{c}{$\mathrm{H} 3: \mathrm{X}^{2}(2, \mathrm{~N}=64)=11.293, \mathrm{p}=0.004$} \\
\hline Format & & High & Mid & Low & Total \\
\hline Request only & Observed Count & 9 & 20 & 10 & 39 \\
& Expected Count & 7.3 & 15.2 & 16.5 & \\
\hline Req + Desc & Observed Count & 3 & 5 & 17 & 25 \\
& Expected Count & 4.7 & 9.8 & 10.5 & \\
\hline Total & & $\mathbf{1 2}$ & $\mathbf{2 5}$ & $\mathbf{2 7}$ & $\mathbf{6 4}$ \\
\hline
\end{tabular}

\footnotetext{
${ }^{\mathrm{i}}$ Expected Counts are the projected frequencies for each condition (or table cell) based on the row and column totals if the null hypothesis is true (i.e., no association between the variables)
} 